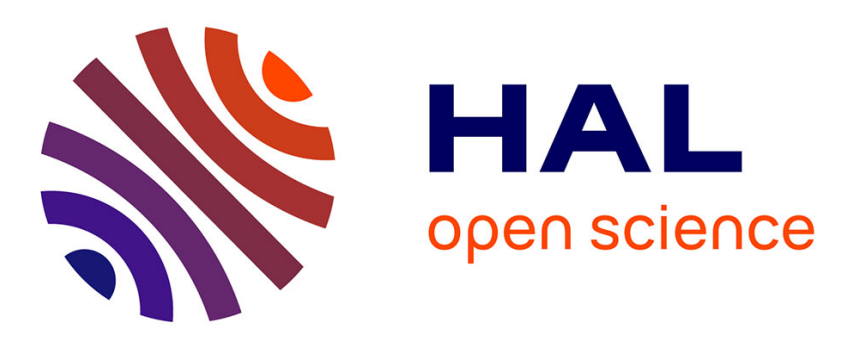

\title{
Detection of organic crystallites in ice using terahertz time-domain spectroscopy
}

Sergey I. Mitryukovskiy, Jean-Francois Lampin, Romain Peretti

\section{To cite this version:}

Sergey I. Mitryukovskiy, Jean-Francois Lampin, Romain Peretti. Detection of organic crystallites in ice using terahertz time-domain spectroscopy. 2018 43rd International Conference on Infrared, Millimeter, and Terahertz Waves (IRMMW-THz 2018), Sep 2018, Nagoya, Japan. paper Th-P1-R1-5, 2 p., 10.1109/IRMMW-THz.2018.8509844 . hal-02334951

\section{HAL Id: hal-02334951 \\ https://hal.science/hal-02334951}

Submitted on 4 Aug 2021

HAL is a multi-disciplinary open access archive for the deposit and dissemination of scientific research documents, whether they are published or not. The documents may come from teaching and research institutions in France or abroad, or from public or private research centers.
L'archive ouverte pluridisciplinaire HAL, est destinée au dépôt et à la diffusion de documents scientifiques de niveau recherche, publiés ou non, émanant des établissements d'enseignement et de recherche français ou étrangers, des laboratoires publics ou privés. 


\title{
Detection of Organic Crystallites in Ice Using Terahertz Time-Domain Spectroscopy
}

\author{
Sergey Mitryukovskiy, Jean-François Lampin and Romain Peretti \\ IEMN, CNRS, Université Lille 1, Villeneuve d'Ascq, 59652 France
}

\begin{abstract}
We report on the detection of a narrow absorption signature of organic crystallites (alpha-lactose monohydrate) in ice using terahertz time-domain spectroscopy.
\end{abstract}

\section{INTRODUCTION}

$\mathrm{T}$ ERAHERTZ time-domain spectroscopy (THz-TDS) is a powerful tool to characterize organic samples and many compounds, like explosives and pharmaceuticals [1-4]. Indeed, THz-TDS study of many samples in their native aqueous environment is limited due to the strong absorption by liquid water or its vapor in the $\mathrm{THz}$ range. However, in aqueous ice there are fewer molecular rotational modes and THz pulses propagate much further $[5,6]$. Thus, it enables the possibility to probe frozen sample such as a frozen product from the Agribusiness with the goal to probe their quality and even more to check if the cold chain had been followed. Still, one needs to go a step further in analyzing iced samples to better benchmark what information will be obtained from such experiments. As a beginning, the detection of sodium chloride ion pairs in ice was reported [5], dielectric constants of $\mathrm{H}_{2} \mathrm{O}$, $\mathrm{D}_{2} \mathrm{O}$ [6] and $\mathrm{Ih}$ ice [7] in $\mathrm{THz}$ range was measured over temperature.

We present a THz-TDS study of iced samples prepared from lactose aqueous solutions, and then of ice with undissolved lactose crystallites. Those samples consist in a step further toward real frozen sample experiments. The observed strong absorption signature of the crystallites allows its identification and demonstrates the perspective of the approach.

\section{RESULTS}

THz absorbance spectra were recorded using a TeraSmart THz-TDS setup by Menlo systems Gmbh [8] placed into a glove box with a nitrogen gas flow to reduce water vapor absorption during the measurement.

An alpha-lactose monohydrate powder obtained from Sigma-Aldrich was used for sample preparation. The lactose powder was dissolved in distilled water to obtain a saturated solution, which was then diluted by distilled water to get several sample solutions with different lactose concentration (namely $0.569 \mathrm{~mol} / \mathrm{L}, 0.285 \mathrm{~mol} / \mathrm{L}, 0.142 \mathrm{~mol} / \mathrm{L}$, and 0.071 $\mathrm{mol} / \mathrm{L})$. We also prepared a sample with the lactose concentration $(\sim 1 \mathrm{~mol} / \mathrm{L})$ higher than the saturation concentration to assure the presence of undissolved lactose crystallites. The sample solutions were contained in 4-mL plastic cuvettes to form rectangular cuboid samples of ice with the base dimensions of $10 \mathrm{~mm} \times 10 \mathrm{~mm}$ (fixed) and the height around $40 \mathrm{~mm}$ (which is approximate due to the nonuniform volume increase during crystallization). The cooling of the samples was performed by placing the cuvettes into a cryogenic vessel filled with liquid nitrogen (the sample with undissolved lactose was shaken and rapidly frozen to keep the uniform distribution of lactose crystallites in ice). The iced samples were then inserted into the path of the $\mathrm{THz}$ pulses.

The retrieved absorbance spectra are presented in the Fig. 1. The absorbance intensity increases with the increase of the lactose concentration. This is due to modification of the ice structure. For the sample with lactose concentration higher than the saturation one, a narrow peak of absorption is observed around $0.53 \mathrm{THz}$, a clear signature of alpha-lactose monohydrate crystallites in ice, which is consistent with the previously reported absorbance spectrum of lactose powder pressed into pallets $[1,9,10]$.

\section{SUMMARY}

The resonant attenuation signature of alpha-lactose

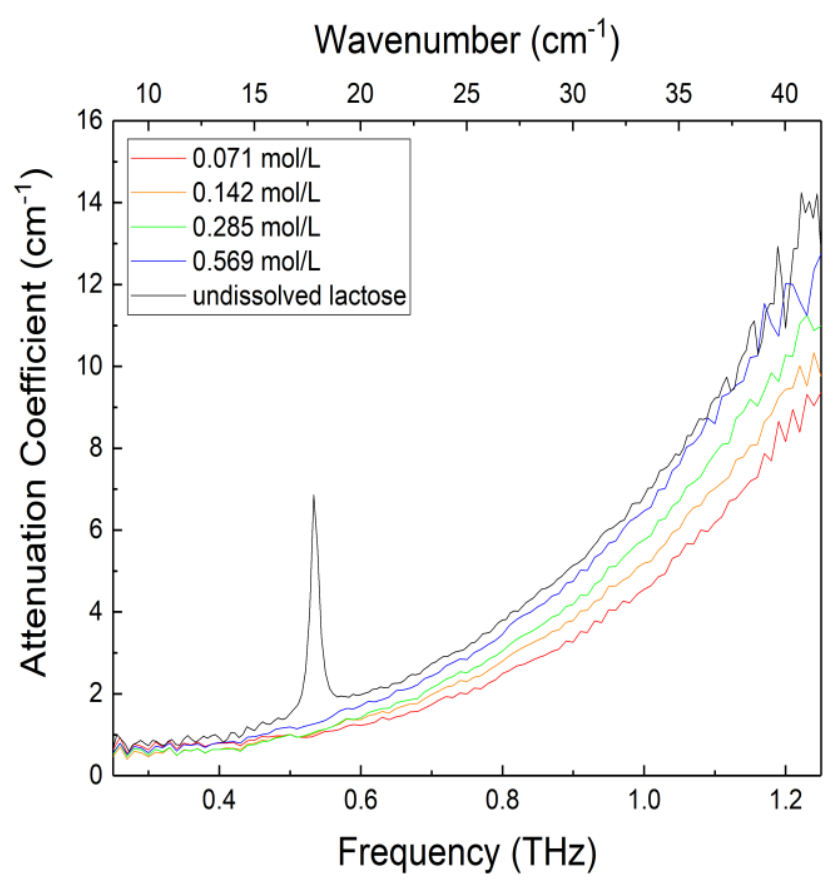

Fig. 1. Attenuation coefficient spectrum of ice prepared from lactose aqueous water solution at different concentrations (color curves) and from the saturated solution with undissolved lactose crystallites (black curve).

monohydrate crystallites in ice was observed by THz-TDS. The use of ice is advantageous for characterization of organic samples and fully compatible with agribusiness industry. At the conference, we will present our further study of various organic structures (carbohydrates)

\section{ACKNOWLEDGMENTS}

This work was partially supported by: i) the international chair of excellence "ThOTroV" from region "Hauts-deFrance"; ii) the welcome talent grant NeFiStoV from European metropole of Lille; iii) the French government 
through the National Research Agency (ANR) under program PIA EQUIPEX LEAF ANR-11-EQPX-0025 and ExCELSiOR ANR 11-EQPX-0015; and iv) the French RENATECH network on micro and nanotechnologies.

\section{REFERENCES}

[1]. B. Fischer, M. Hoffmann, H. Helm, G. Modjesch and P.Uhd. Jepsen, "Chemical recognition in terahertz time-domain spectroscopy and imaging," Semiconductor Science and Technology, vol. 20, pp. 246-253, 2005.

[2]. B. Ferguson and X.-C. Zhang, "Materials for terahertz science and technology," Nature Materials, vol. 1, p. 26, 2002.

[3]. P. U. Jepsen, D. G. Cooke, and M. Koch, "Terahertz spectroscopy and imaging - Modern techniques and applications," Laser Photonics Review, vol. 5, p. 124, 2011.

[4]. F. D’Angelo, Z. Mics, M. Bonn, and D. Turchinovich, "Ultra-broadband $\mathrm{THz}$ time-domain spectroscopy of common polymers using $\mathrm{THz}$ air photonics", Optics Express, vol. 22, p. 12475, 2014.

[5]. R. Rungsawang, Y. Ueno and K. Ajito, "Detecting a sodium chloride ion pair in ice using terahertz time-domain spectroscopy," Analytical Advances, vol. 23, pp. 917-920, July, 2007.

[6]. K. Takeya, T. Fukui, R. Takahashi and K. Kawase, "Dielectric constants of $\mathrm{H}_{2} \mathrm{O}$ and $\mathrm{D}_{2} \mathrm{O}$ ice in the terahertz frequency regime over a wide temperature range," Journal of Optics, vol. 16, p. 094005, 2014.

[7]. C. Zhang, K.-S. Lee, X.-C. Zhang, X. Wei and Y. R. Shen, "Optical constants of ice Ih crystal at terahertz frequencies", Applied Physics Letters, vol. 79, p. 491, 2001

[8]."http://www.menlosystems.com/en/products/thz-time-domainsolutions/terasmart-terahertz-spectrometer/." [Online]. Available: http://www.menlosystems.com/en/products/thz-time-domain-solutions/terasmartterahertz-spectrometer/

[9]. E.R. Brown, J.E. Bjarnason, A.M. Fedor and T.M. Korter, "On the strong and narrow absorption signature in lactose at $0.53 \mathrm{THz}$," Applied Physics Letters, vol. 90, p. 061908, 2007.

[10]. D.G. Alias, A.M. Fedor, T.M. Korter, J.E. Bjarnson, E.R. Brown, "Assignment of the lowest-lying $\mathrm{THz}$ absorption signatures in biotin and lactose monohydrate by solid-state density functional theory", Chemical Physics Letters, vol. 440, p.203, 2009. 